\title{
Role of marine mammals in aquatic ecosystems
}

\author{
W. D. Bowen* \\ Marine Fish Division, Bedford Institute of Oceanography, Department of Fisheries and Oceans, Dartmouth, Nova Scotia, \\ Canada B2Y 4 A2
}

\begin{abstract}
Marine mammals are consumers of production at most trophic levels. Because of their large body size and abundance, they are thought to have a major influence on the structure and function of some aquatic communities. However, there is relatively little empirical evidence of these roles. There are several reasons for this: research in marine ecosystems is expensive, manipulative experiments are rarely possible, interactions occur at quite different spatial and temporal scales making measurement of system properties difficult, and there is an inherent indeterminacy in the behavior of these complex systems which makes simplifying deterministic explanations problematic. Nevertheless, experimental studies have demonstrated clearly that sea otters Enhydra lutris strongly affect kelp forest communities through predation on sea urchins, they also suggest that gray whale Eschrichtius robustus and walrus Odobenus rosmarus feeding can affect the structure of benthic invertebrate communities, and that dugongs Dugong dugon may cultivate the seagrass community upon which they feed. Changes in the abundance of many species following large-scale harvesting of whales in the Southern Ocean and perhaps also in the Bering Sea further suggest top-down effects of marine mammals. Nevertheless, the top-down effects of marine mammal predation in the open ocean remain poorly understood.
\end{abstract}

KEY WORDS: Marine mammals · Ecological role - Top-down effects - Aquatic ecosystems

\section{INTRODUCTION}

Marine mammals are major consumers of production at most trophic levels from primary production (i.e. sirenians) to predatory fish and even to other marine mammals, as in the case of killer whales Orcinus orca, some pinnipeds, and the polar bear Ursus maritimus. Because of their large body size and abundance, they are thought to have a major influence on the structure and function of some marine communities (Estes 1979, Ray 1981, Laws 1984, Katona \& Whitehead 1988). The long-standing debate surrounding ecological interactions between marine mammals and fisheries is rooted in the belief that marine mammals can have significant effects on prey populations that are of commercial interest to humans (e.g. Gulland 1987, Anon. 1992, Butterworth 1992, Punt \& Butterworth 1995) and that fisheries may impact marine mammals (e.g. NRC 1996). An understanding of the role of marine mammals in marine ecosystems is important because it provides a context within which to evaluate the potential

\footnotetext{
•E-mail: d_bowen@bionet.bio.ns.ca
}

impact of their predation on prey populations and community structure, and the impact of variation in prey populations, of harvesting by humans, and environmental change on the dynamics of marine mammals. This understanding in turn can help foster the rational discussion of the conservation and management of marine mammals.

What do we mean by the term 'role'? In an ecological sense, role implies something about the functional significance of a species or other taxon. All marine mammals must influence in some way the ecosystems of which they are a part. Katona \& Whitehead (1988) suggest that we might consider this question by 'asking whether the extinction of all cetaceans would create any noticeable difference in ecosystem function'. Of course, we could pose the same question about other groups of marine mammals and we could substitute large variation in distribution and abundance for extinction. Implicit here is the trophodynamic function of marine mammals as consumers and the effect of this consumption on species interactions and community structure. This is referred to as the top-down view of ecological interactions (e.g. Brooks \& Dodson 1965 , 
Paine 1966, Strong 1992). However, marine mammals may also play an important role in shaping the behavior and life history traits of prey species and competitors, in nutrient storage and recycling, and in modifying benthic habitats (see Katona \& Whitehead 1988).

It may seem puzzling that the ecological role of marine mammals is still so poorly understood, given the importance which society attaches both to the harvesting of marine living resources and to marine mammals as among the most visible components (i.e. as 'charismatic megafauna') of marine ecosystems. One major reason for this lack of understanding is that in attempting to determine the role of marine mammals we are faced with the intersection of no less than 3 inexact disciplines: marine ecology, marine mammal population biology, and fisheries ecology (see Katona \& Whitehead 1988). In each of these complex fields, research is expensive, manipulative experiments are rarely possible, interactions occur at quite different spatial and temporal scales making measurement of system properties difficult, and there is an inherent indeterminacy in the behavior of these complex systems which makes simplifying deterministic explanations problematic. This means that understanding comes slowly and mostly through the correlation of observed events.

Nevertheless, there are several systems where experiments have revealed rather clear evidence about the function of marine mammal predation. In other systems, studies conducted during large-scale changes in the abundance of predator and/or prey have provided insight into the role of marine mammals. In these cases, we are generally less confident in our conclusions because we are dealing with the correlation of an uncontrolled event (say, the rapid overexploitation of a whale or seal population) with other changes in the ecosystem. Depending on the nature of the uncontrolled event, such studies are referred to as observational, analytical, or intervention studies (Eberhardt \& Thomas 1991), as compared to manipulative, controlled experiments.

Insight into the role of marine mammals in aquatic ecosystems might also be gained by analogy with studies of terrestrial carnivores (e.g. Skogland 1991) or fish predation in freshwater ecosystems (Kerfoot \& Sih 1987). There is no doubt some benefit in this comparative approach. However, it is important to bear in mind that there may be reasons to expect differences in the structure and function of marine and terrestrial ecosystems that could bear on the function of predation (Steele 1985, 1991). For example, Whitehead \& Walde (1992) suggest that habitat geometry (i.e. 2 vs 3 dimensions) may affect foraging behavior of top predators which in turn has a bearing on structure observed at the community or ecosystem level. Does this mean that marine mammal predation functions differently than does mammalian predation on land? At this time we simply do not know, but it is important to consider in attempting to draw conclusions from much better understood freshwater and terrestrial systems.

\section{CONSUMPTION AS A MEASURE OF ECOLOGICAL ROLE}

The flow of energy through the cetacean component of marine ecosystems has been viewed as evidence of their ecological significance (Kanwisher \& Ridgway 1983, Katona \& Whitehead 1988). Kanwisher \& Ridgway (1983) suggested that cetaceans as a group, and sperm whales Physeter macrocephalus alone, might consume a greater quantity of prey than all human fisheries combined. Bax (1991) compared estimates of fish consumption by fish, marine mammals, birds, and fisheries in 6 ecosystems. In each of these, estimates of fish predation on fish far exceeded predation from other sources. In 3 of these ecosystems, marine mammals were thought to consume the second largest component of fish biomass. Based on available analyses, marine mammal predation on fish appears to be particularly large off the northeastern United States (including Georges Bank) where about $36 \%$ is due to whales (Overholtz et al. 1991), and in the Barents and Norwegian Seas where $45 \%$ is due to whales (Bax 1991). Recent work by Kenney et al. (in press) suggests that marine mammals (mainly whales) are even more important consumers of fish and squid biomass off the northeastern United States than previously estimated by Overholtz et al. (1991). Thus, better data may reveal that marine mammals are more important consumers of prey in a greater number of ecosystems than is currently thought to be the case.

Changes in the patterns of food consumption by marine mammals, particularly the large whales, resulting from the overexploitation of marine mammals in the Southern Ocean have been extensively analyzed by Laws $(1977,1984,1985)$ as evidence of the role of large cetaceans. Both in the Southern Ocean (Laws 1985) and in the Bering Sea (NRC 1996), patterns of food consumption by large cetaceans are thought to have had strong effects on community structure (see below).

Although considerably smaller in body size than the large cetaceans, pinnipeds are likely to be ecologically significant consumers in some marine ecosystems as well. For example, it is difficult to imagine that 12 to 15 million crabeater seals Lobodon carcinophagus are not important in the structure and function of the Antarctic ecosystem (Laws 1984, 1985). In the northern hemisphere, the 3 harp seal Phoca groenlandicus popula- 
tions combined number roughly 8 million individuals and the northwest Atlantic population alone, at $4.3 \mathrm{mil}-$ lion, is estimated to have consumed about 7 million $t$ of prey in 1994 (Anon. 1995). Nevertheless, in all these cases, caution is needed in interpreting food consumption at large spatial scales and over many species as a measure of ecological importance (see below).

\section{BEYOND CONSUMPTION}

Consumption by a marine mammal population or assemblage of species will often be a very large figure which alone suggests significance, but marine mammal predation can be properly evaluated only when compared to other sources of consumption. There are 2 reasons for this. First, ecological interactions involving marine mammals and their prey can be complex. Depending on the nature of the food web within which this predation occurs, the effects of marine mammal consumption can be quite different (Harwood 1983, Beverton 1985). Second, to assess impact we need to know the mortality rate generated by this consumption, how this mortality rate compares to other sources of mortality on prey populations, how predation responds to changes in prey abundance, and the effect of this predation on prey dynamics (Beverton 1985 , Butterworth 1992, Punt \& Butterworth 1995, Mohn \& Bowen 1996). The distinction between consumption and mortality rate is fundamental to the assessment of the impact of marine mammal predation on fish populations of commercial importance. However, commonly impact is inferred simply from the amount of prey consumed. The ratio of the amount of prey consumed by marine mammals relative to a fishery has also been used as a measure of importance of marine mammal consumption (Beverton 1985). This ratio is informative when both the marine mammal and the fishery take similar size prey. Unfortunately, many pinnipeds tend to consume significantly smaller prey than those taken by fisheries, making the interpretation of the above ratio problematic.

Mohn \& Bowen (1996) modelled the impact of grey seal predation mortality on Atlantic cod on the Eastern Scotian shelf off Nova Scotia. They used 2 models to describe the response of grey seal predation to changes in cod abundance under 2 assumptions about the level and pattern of age-specific natural mortality of cod. Under either model, grey seal predation mortality was only 10 to $20 \%$ of the estimated mortality caused by the fishery. The models generally predicated that future recruitment of age 1 cod to the cod population would be significantly reduced due to grey seal predation, but these predictions were quite sensitive to the assumption that seal predation mortality was additive. It is not known if this assumption is true Mohn \& Bowen (1996) concluded that uncertainty in assessing the impact of grey seal predation on Atlantic cod Gadus morhua resulted, to a great extent, from the lack of information on the natural mortality rate of young cod, the nature of the interactions (i.e. additive vs compensatory) among the components of natural mortality on young cod, and the functional response of grey seals to changes in prey abundance. Until these relationships are better understood, conclusions about the impact of seal predation on cod dynamics must be viewed with caution.

\section{NUTRIENT RECYCLING}

Kanwisher \& Ridgway (1983) speculated that some cetaceans may have an important ecological role in the recycling of nutrients by feeding at depth and then defecating in the euphotic zone. Katona \& Whitehead (1988) attempted to evaluate this hypothesis by studying sperm whales off the Galapagos Islands, Ecuador. Using estimates of whale population density, rate of food consumption, and the nitrogen content of oceanic squid, Katona \& Whitehead (1988) were able to show that sperm whales could likely contribute only about $0.04 \%$ of the nitrogen content of primary production west of the Galapagos. These calculations do not provide a basis to draw firm conclusions; however, they do suggest that, in the open ocean, marine mammals are unlikely to play a significant role in the recycling of nutrients. In other habitats, the situation may be different. For example, do sirenians play a role in the nutrient dynamics of coastal seagrass communities?

Large cetaceans may continue to play an important ecological role even after death through the downward transfer of nutrients to benthic communities (Katona \& Whitehead 1988). Smith et al. (1989) discovered a deep-sea, chemosynthetic community supported by a $20 \mathrm{~m}$ whale skeleton in the Santa Catalina Basin off California, USA. Many of the larger bones were covered with white microbial mats and 6 metazoan species not previously recorded from the area. Rough calculations suggest that there would be 1 reductant-rich whale skeleton per $300 \mathrm{~km}^{2}$ based only on the abundance of the gray whale. Smith et al. (1989) hypothesize that large cetacean carcasses may be an important vehicle for the dispersal of deep-sea chemosynthetic communities over large areas.

\section{CO-EVOLUTION OF PREDATOR AND PREY}

The co-evolution of predator and prey has received considerable attention in terrestrial and aquatic envi- 
ronments (e.g. Endler 1991). Katona \& Whitehead (1988) discuss the role of cetaceans in the co-evolution of predator and prey. They pointed out that sonar and the range of prey sizes included in filter feeding baleen whales have likely had important effects on the behavior of prey. One example of this may be found in mysticetes. Individual prey such as herring and krill theoretically minimize their risk of predation by seabirds, seals and larger fish by forming tight schools. However, when attacked by bulk-feeders such as baleen whales, individuals should do better by scattering. There is evidence that capelin respond in this way when being attacked by humpback whales (Katona \& Whitehead 1988). Predation by polar bears has undoubtedly played a role in the selection by ringed seals Phoca hispida of fast-ice breeding habitat which is suitable for the construction of birth lairs (Stirling 1977). This antipredator behavior is seen in only 1 other pinniped species. Although marine mammal predators are likely to have played a role in shaping the behavior of their prey in both ecological and evolutionary time, this has not been carefully investigated.

\section{COMMUNITY STRUCTURE}

The role of the sea otter in structuring nearshore communities is well documented (Estes \& Palmisano 1974, Simenstad et al. 1978, Estes \& Duggins 1995). Sea otters are predators on invertebrates including sea urchins, clams, and crabs that occupy the near-shore community. Sea urchins graze on kelp, a major component of these near-shore environments. The ecological interactions among sea otters, urchins, and kelp communities have been studied by several investigators, particularly Estes and his colleagues, for many years. In general, these studies have demonstrated that when sea otters are present, kelp forests are allowed to develop because otter predation on urchins reduces kelp grazing. Much of the reduction in grazing is because otters tend to forage initially on the very large urchins which are the most effective grazers of kelp. When otters invade a near-shore community the large urchins are the first to decline in abundance, until over time most of the urchins that are present are small and not very effective at reducing kelp biomass. Thus, in general, the kelp populations are allowed to increase in abundance as the sea otters become established. This allows other populations, such as the fish species that occupy kelp cover, to increase in abundance and hence, the community becomes more diverse. This general pattern is somewhat complicated by events such as storms that damage the kelp communities, or by physical features such as currents or temperature changes that may influence reproductive patterns of both kelp and sea urchins. However, the long-term trends produce the general picture described above (Estes \& Duggins 1995).

The clearest example of the ecological role of pinniped predation comes from a study of lakes. But even here, the evidence is only indirect. Power \& Gregoire (1978) compared the fish communities in 9 northern Quebec (Canada) lakes which did not have seals with Lower Seal Lake which supported a population of harbor seals. Although the size of this population was unknown, seals were observed by the authors in one year and observations of seals were reported to them in the following year. Surveys of the fish communities in these lakes showed that Lower Seal Lake differed from the other lakes in the relative abundance of lake trout Salvelinus fontinalis and brook trout S. namaycush. In Lower Seal Lake, brook trout was the dominant species whereas lake trout was dominant in all other lakes. Power \& Gregoire (1978) also noted that changes in life history characteristics of lake trout in Lower Seal Lake were consistent with effects associated with heavy exploitation. These lake trout were on average smaller, younger, grew more rapidly, and matured earlier than lake trout in neighboring lakes. Power \& Gregoire (1978) concluded that seal predation was responsible for both the changes in community structure and life-history traits of fish species in Lower Seal Lake. They observed that seal predation had apparently targeted species, such as lake trout, that aggregated in lakes during spawning. Brook trout became the dominant species in Lower Seal Lake because its spawning sites were widely dispersed in many small streams, and juveniles spent the first 2 to 3 yr of life in streams where they were reasonably protected from seal predation. Although the conclusions of Power \& Gregoire (1978) are compelling on the surface, they are based on strong inference rather than direct empirical evidence. For example, we do not know if there were sufficient seals in the lake to account for the effects observed. Experimental introductions of harbor seals into other lakes in this area offer exciting opportunities for learning more about the role of seal predation on fish communities (McLaren \& Smith 1985).

Herbivory can have strong impacts on the structure of terrestrial plant communities. Sirenians are major consumers of the seagrasses in tropical coastal ecosystems. Preen (1995) studied the impact of dugong foraging on a seagrass community at the southern limit of their range in eastern Australia. Dugongs are the main consumers of seagrasses. They generally feed in large groups and may graze at the same location for extended periods. Compared to non-grazed areas, grazing resulted in a reduced density of seagrass shoots by 65 to $95 \%$, above-ground biomass by 73 to $96 \%$ and 
below-ground biomass by 31 to $71 \%$ at 3 sites. In exclosure experiments, intensive grazing resulted in a change in the species composition of the seagrass complex, favoring the more nutritious, rapidly growing species preferred by dugongs. Preen (1995) suggested that dugong foraging be termed cultivation grazing in that it can improve the quality of the dugong's diet by preventing the expansion of the dominant, but less nutritious, slow-growing species of seagrass. Additional studies over longer time periods will be needed to confirm this suggestion, but it does appear that dugong grazing, and similar foraging by manatees, may well have strong impacts on the structure of seagrass communities.

Estes (1979) and Ray (1981) used the concept of rand K-selection as a basis for theoretical arguments about the ecological role of marine mammals. In general, K-selected species (i.e. long-lived species with low reproductive rates and high relatively uniform abundance) are predicted to have the greatest effect in structuring their ecosystems (Ray 1981). The argument here is that these species function in some analogous sense as the 'forests of the oceans' in tying up large amounts of nutrients and being able to buffer shortterm fluctuations in resource availability. The cascading changes in community structure hypothesized to have occurred in both the Southern Ocean (Laws 1985) and the Bering Sea (NRC 1996) may be illustrations of the effect of the marine mammal 'clear cutting' on marine ecosystems.

In the Southern Ocean, intense commercial exploitation of marine mammals brought some species of seals and whales near extinction in the nineteenth and early twentieth centuries (Laws 1977). This overexploitation amounted to nothing less than an enormous uncontrolled 'experiment' (Laws 1985) or perhaps more correctly an 'observational study' in the sense of Eberhardt \& Thomas (1991). What have we learned, as a result of this perturbation, about the role of marine mammals in this cold water ecosystem?

Six baleen whale species and 1 subspecies inhabit the Southern Ocean along with the sperm whale and 11 species of small toothed whales which penetrate south of the Antarctic Convergence (Laws 1985). Krill is the major food of the baleen whales. Sperm whales feed mainly on deep-sea squids, whereas the other odontocetes feed on a mixture of squids and fishes. The abundance of baleen whales and the sperm whale probably declined by more than $50 \%$ between 1904 and 1973 as result of intense exploitation. Because the largest species were taken first, the cetacean biomass declined from an estimated 45 million t to only 9 million t over this same period (Laws 1985).

Six species of pinnipeds are found also in the Southern Ocean. Both the Antarctic fur seal Arctocephalus gazella and southern elephant seal Mirounga leonina were brought to near extinction in the nineteenth century, but their numbers have recovered substantially. Of these 6 species, the crabeater seal Lobodon carcinophagus depends almost entirely on krill, whereas Antarctic fur seals and leopard seals Hydrurga leptonyx feed mainly on krill at certain times of the year.

Laws (1985) estimated that this enormous reduction in the biomass of large whales may have released some 150 million $t$ of krill annually to predators (the remaining whales, seals, seabirds, and fish). We can gain a sense of the magnitude of this ecological perturbation by comparing this biomass of krill with the 101 million $t$ landed in 1993 by the world's combined marine fisheries (FAO 1995). Although many of the estimates of population food consumption are necessarily tentative given the quality of data, Laws (1985) calculated that much of this krill was redistributed to seals (the crabeater seal and the Antarctic fur seal) and birds, both of which have become considerably more abundant over the past 3 decades. Chinstrap Pygoscelis antarctica, Adelie $P$. adeliae, and macaroni Eudyptes chrysolophus penguins, which together account for about $90 \%$ of the Antarctic avian biomass, have also increased in numbers. The present minke whale population is perhaps twice that which existed before whaling, possibly a response to the great reduction in blue whale numbers (Laws 1985). Laws (1985) further points out that the increase in king penguins may have been caused by the increase in krill-feeding squids, which in turn became more abundant because of decreases in the number of sperm whales. It seems clear that the relative abundances of krill consumers and other prey in the Southern Ocean are quite different today than they were prior to the exploitation of the large whales. Although we cannot be certain, it seems reasonable that the population increases of the above species are due to the increase in food availability brought about by the overexploitation of the large whales (Laws 1985).

Large-scale, intensive harvesting of fish and whales occurred during the 1950s, 1960s, and early 1970s in the Bering Sea and Gulf of Alaska. The stocks of large whales, flatfishes, herring, and slope rockfishes were severely reduced during this period (NRC 1996). Although quantitative estimates are not available, this reduction in major consumers of krill and other zooplankton is thought to have released food for other species. This increased availability of krill and other zooplankton, coupled with environmental changes, may have led to the eastern Bering Sea fish assemblage becoming dominated by walleye pollock Theragra chalcogramma. In the 1970 s and 1980s, although some fish populations grew rapidly, a number of forage species appear to have declined. In the face of these 
changes and continuing fisheries, both harbor seals Phoca vitulina and Steller sea lions Eumetopias jubatus have declined dramatically over the past several decades. These declines appear to be related to a lack of food, with juvenile pinnipeds likely affected most severely. It has been hypothesized that a combination of environmental change and human exploitation of krill and zooplankton predators (both whales and fish) resulted in changes to the ecosystem that have been detrimental to pinnipeds (NRC 1996).

\section{Modification of benthic habitat}

Some marine mammals may play a role in the physical restructuring of the benthos. Nerini (1984) estimated that gray whales Eschrichtius robustus turn over between 9 and $27 \%$ of the benthic substrate in the northern Bering Sea annually. This disturbance may help to maintain early colonizing species at higher abundance than would otherwise be the case and may be important in providing habitat for the young of their primary amphipod prey. Oliver \& Slattery (1985) examined the effects of gray whale feeding at St. Lawrence Island in the Bering sea and on the west side of Vancouver Island, British Columbia, Canada. At both sites, feeding was highly disruptive, amphipod scavengers quickly colonized experimental feeding pits, and various invertebrates were attracted to the debris that settled in the pits after gray whales had finished feeding. Scavengers and other invertebrates attracted to debris were 2 to 30 times more abundant within feeding pits than in adjacent sediments. Over a longer period, tube dwelling species gradually increased inside feeding pits. Although these effects were transient (i.e. biomass and community structure likely recovered within several months), feeding disturbance appears to help maintain the sand substrate by suspending fine sediments (Johnson \& Nelson 1984). These sandy sediments support the dense beds of amphipods that gray whales consume and thus Oliver \& Slattery (1985) suggest that feeding disturbance may result in higher densities of prey over a larger spatial scale.

Walruses are highly specialized consumers of infaunal bivalves. In the process of feeding, they produce many pits and furrows in soft sediments. Walruses may structure the benthic fauna by selectively feeding on older individuals of a few species of bivalve molluscs (Fay \& Stoker 1982). Ingestion and defecation by walruses may result in substantial redistribution of sediment which may favor colonization of some species, but not others (Fay et al. 1977, Oliver et al. 1983). Oliver et al. (1985) experimentally investigated the effects of walrus feeding on macrobenthic assemblages at several sites in the Bering Sea. Walrus feed- ing appeared to affect community structure in 3 ways: by providing food for scavengers such as sea stars Asterias amurensis and brittle stars Amphiodia craterodmeta, by providing habitat under discarded bivalve shells, and by reducing the abundance of macroinvertebrates in feeding pits compared to surrounding sediments. However, the effect of walrus feeding behavior on macroinvertebrate assemblages over periods greater than a few months and at large spatial scales remains poorly understood.

\section{CONCLUSIONS}

We have much to learn about the ecological roles of marine mammals, but there is evidence that the abundance and distribution of marine mammals can have important effects on the structure and function of some ecosystems. However, despite the suggestive analyses of the ecosystem responses to large-scale changes in marine mammal abundance, we have little understanding of the role of marine mammal predation in the open ocean. Developing a better understanding of the role of marine mammals in marine ecosystems is one of the greatest challenges facing those interested in marine mammal ecology. Conservation biology, single-species and multi-species resource management and ecosystem management will all benefit from this understanding. However, this understanding will likely come slowly; the product of long-term, interdisciplinary research. Interdisciplinary research is essential because the spatial and temporal scales of marine mammal predation may be quite different from those of interest to fisheries ecologists and oceanographers (e.g. NRC 1996, Iverson et al. 1997). For example, in studies of prey selection by pinnipeds, prey abundance data often come from fisheries trawl surveys which typically sample large areas at a low sampling intensity (e.g. Bowen \& Harrison 1994). Although the use of these fisheries data provides a useful first step, interpretation of the results of such efforts is limited given the coarse spatial sampling of these surveys relative to that which is likely relevant to marine mammals. A preferable approach is to sample both prey abundance and the diet of predator at the same time (e.g. Murison \& Gaskin 1989, Sinclair et al. 1994, Haug et al. 1995), but to do so requires a level of research integration that is still uncommon.

We face great difficulties in understanding marine ecosystems. Mathematical models, manipulation experiments, and the search for large-scale patterns in species interactions are all useful approaches. Given that each approach has strengths and weaknesses, the use of different approaches ought to be encouraged (Lawton 1996). 
Acknowledgements. 1 am grateful to S. J. Iverson, I. McLaren, and $H$. Whitehead for commenting on an earlier draft of the paper and to the improvements suggested by the 3 reviewers. J. R. Reynolds III and H. Whitehead kindly directed me to important sirenian and cetacean literature.

\section{LITERATURE CITED}

Anon. (1992) Marine mammal/fishery interactions: analysis of cull proposals. Report of the meeting of the Scientifc Advisory Committee of the Marine Mammal Action Plan, Liege, Belgium. United Nations Environmental Program (OCA)/MM.SAC.3/1

Anon. (1995) Report on the status of harp seals in the northwest Atlantic. Stock Status Report 95/7, Department of Fisheries and Oceans, Ottawa

Bax NJ (1991) A comparison of the fish biomass flow to fish, fisheries, and mammals in six marine ecosystems. ICES Mar Sci Symp 193:217-224

Beverton RJH (1985) Analysis of marine mammal-fisheries interaction. In: Beddington JR, Beverton RJH, Lavigne DM (eds) Marine mammals and fisheries. George Allen \& Unwin, London, p 3-33

Bowen WD, Harrison G (1994) Offshore diet of grey seals Halichoerus grypus near Sable Island, Canada. Mar Ecol Prog Ser 112:1-11

Brooks J, Dodson SI (1965) Predation, body size, and composition of plankton. Science 150:28-35

Butterworth DS (1992) Will more seals result in reduced fishing quotas? S Afr J Sci 88:414-416

Eberhardt LL, Thomas JM (1991) Designing environmental field studies. Ecol Monogr 61:53-73

Endler JA (1991) Interactions between predators and prey. In: Krebs JR, Davies NB (eds) Behavioural ecology. An evolutionary approach. Blackwell Scientific Publications, Cambridge, p 169-201

Estes JA (1979) Exploitation of marine mammals: r-selection of K-strategists? J Fish Res Bd Can 36:1009-1017

Estes JA, Duggins DO (1995) Sea otters and kelp forests in Alaska: generality and variation in a community ecological paradigm. Ecol Monogr 65:75-100

Estes JA, Palmisano JF (1974) Sea otters: their role in structuring nearshore communities. Science 185:1058-1060

FAO (1995) Fisheries statistics, Vol 77, 1993. FAO Fish Ser 45

Fay FH, Feder HM, Stoker SW (1977) An estimation of the impact of the Pacific walrus population on its food resources in the Bering Sea. Final Report U.S. Marine Mammal Comm, PB-273-505, Natl Tech Info Serv, Springfield, VA

Fay FH, Stoker SW (1982) Reproductive success and feeding habits of walruses taken in 1982 spring harvest, with comparisons from previous years. Final Rep Eskimo Walrus Comm, Nome, AK

Gulland JA (1987) Seals and fisheries: a case for predator control? Trends Ecol Evol 2:102-103

Harwood J (1983) Interactions between marine mammals and fisheries. Adv Appl Biol 8:189-214

Haug T, Gjosaeter H, Lindstrom U, Nilssen KT (1995) Diet and food availability for north-east Atlantic minke whales ( $B a 1$ aenoptera acutorostrata), during the summer of 1992. ICES J Mar Sci 52:77-86

Iverson SJ, Frost KJ, Lowry LF (1997) Fatty acid signatures reveal fine scale structure of foraging distribution of harbor seals and their prey in Prince William Sound. Mar Ecol Prog Ser 151:255-271

Johnson KR, Nelson CH (1984) Side-scan sonar assessment of gray whale feeding in the Bering Sea. Science 225: $1150-1152$

Kanwisher JW, Ridgway SH (1983) The physiological ecology of whales and porpoises. Sci Am 248:110-120

Katona S, Whitehead H (1988) Are Cetacea ecologically important? Oceanogr Mar Biol Annu Rev 26:553-568

Kenney RD, Scott GP, Thompson TJ, Winn HE (in press) Estimates of prey consumption and trophic impacts of cetaceans in the U.S. northeast continental shelf ecosystem. J Northw Atl Fish Sci

Kerfoot WC, Sih A (1987) Predation: direct and indirect impacts on aquatic communities. University Press of New England, Hanover, $\mathrm{NH}$

Laws RM (1977) The significance of vertebrates in the Antarctic marine ecosystem. In: Llano GA (ed) Adaptation within Antarctic ecosystems. 3rd Symposium on Antarctic Biology. Smithsonian Institution, Washington, DC, p $411-438$

Laws RM (1984) Seals. In: Laws RM (ed) Antarctic ecology. Academic Press, London, p 621-716

Laws RM (1985) The ecology of the Southern ocean. Am Sci $73: 26-40$

Lawton JH (1996) Patterns in ecology. Oikos 75:145-147

McLaren IA, Smith TG (1985) Population ecology of seals: retrospective and prospective views. Mar Mamm Sci 1:54-83

Mohn R, Bowen WD (1996) Grey seal predation on the eastern Scotian Shelf: modelling the impact on Atlantic cod. Can J Fish Aquat Sci 53:2722-2738

Murison LD, Gaskin DE (1989) The distribution of right whales and zooplankton in the Bay of Fundy, Canada. Can J Zool 67: 1411-1420

Nerini M (1984) A review of gray whale feeding ecology. In: Jones ML, Swartz SL, Leatherwood S (eds) The gray whale, Eschrichtius robustus. Academic Press, Orlando, FL. p 423-450

NRC (1996) The Bering Sea ecosystem. National Research Council, Washington, DC

Oliver JS, Kvitek RG, Slattery PN (1985) Walrus feeding disturbance: scavenging habits and recolonization of the Bering Sea benthos. J Exp Mar Biol Ecol 91:233-246

Oliver JS, Slattery PN (1985) Destruction and opportunity on the sea floor effects of gray whale feeding. Ecology 66 : 1965-1975

Oliver JS, Slattery PN, O'Conner EF, Lowry LF (1983) Walrus, Odobenus rosmarus, feeding in the Bering Sea: a benthic perspective. Fish Bull 81:501-512

Overholtz WJ, Murawski SA, Foster KL (1991) Impact of predatory fish, marine mammals, and seabirds on the pelagic fish ecosystem of the northeastern USA. ICES Mar Sci Symp 193:198-208

Paine RT (1966) Food web complexity and species diversity. Am Nat 100:65-75

Power G, Gregoire J (1978) Predation by freshwater seals on the fish community of Lower Seal Lake, Quebec. J Fish Res Bd Can 35:844-850

Preen A (1995) Impacts of dugong foraging on seagrass habitats: observational and experimental evidence for cultivation grazing. Mar Ecol Prog Ser 124:201-213

Punt AE, Butterworth DS (1995) The effects of future consumption by the Cape fur seal on catched and catch rates of the Cape hakes. 4. Modelling the biological interaction between Cape fur seals Arctocephalus pusillus pusillus and the Cape hakes Merluccius capensis and $M$. paradoxus. S Afr J Mar Sci 16:255-285

Ray GC (1981) The role of large organisms. In: Longhurst AR (ed) Analysis of marine ecosystems. Academic Press, London, $p$ 397-413 
Simenstad CA, Estes JA, Kenyon KW (1978) Aleuts, sea otters, and alternate stable-state communities. Science 200:403-411

Sinclair E, Loughlin T, Pearcy W (1994) Prey selection by northern fur seals (Callorhinus ursinus) in the eastern Bering Sea. Fish Bull 92:144-156

Skogland T (1991) What are the effects of predators on large ungulate populations? Oikos 61:401-411

Smith CR, Kukert $H$, Wheatcroft RA, Jumars PA, Deming JW (1989) Vent fauna on whale remains. Nature 341:27-28

Steele JH (1985) A comparison of terrestrial and marine ecological systems. Nature 313:355-358

Editorial responsibility: Otto Kinne (Editor),

Oldendorf/Luhe, Germany
Steele JH (1991) Marine functional diversity. BioSci 41:470-474 Stirling I (1977) Adaptations of Weddell and ringed seals to exploit the polar fast ice habitat in the absence or presence of surface predators. In: Llano GA (ed) Adaptations within antarctic ecosystems. Smithsonian Institution, Washington, DC, p 741-748

Strong DR (1992) Are trophic cascades all wet? Differentiation and donor-control in speciose ecosystems. Ecology 73: $747-754$

Whitehead $\mathrm{H}$, Walde SJ (1992) Habitat dimensionality and mean search distances of top predators: implications for ecosystem structure. Theor Pop Biol 42:1-9

Submitted: June 20, 1997; Accepted: September 18, 1997 Proofs received from author(s): October 20, 1997 